\section{Original Article}

Dr. Mohammad Ali Akbor Polan Division of Clinical Cariology and Endodontology

Dept. of Oral Rehabilitation, School of Dentistry

Health Sciences University of Hokkaido

Sapporo, Hokkaido, Japan

Dr. Nahid Al Noman

Division of Clinical Cariology and Endodontology

Dept. of Oral Rehabilitation, School of Dentistry

Health Sciences University of Hokkaido

Sapporo, Hokkaido, Japan

Dr. Chowdhury Moin Jan Dept. of Conservative Dentistry \& Endodontics

City Dental College, Dhaka

Dr. Md. Riasat Hasan

Dept. of Conservative

Dentistry \& Endodontics

City Dental College, Dhaka

Prof. Takashi Saito DDS, PhD

Division of Clinical Cariology and Endodontology

Dept. of Oral Rehabilitation, School of Dentistry

Health Sciences University of Hokkaido

Sapporo, Hokkaido, Japan

Correspondence to:

Dr. Mohammad Ali Akbor Polan $\mathrm{BDS}, \mathrm{MPH}$

Division of Clinical Cariology \& Endodontology Dept. of Oral Rehabilitation, School of Dentistry

Health Sciences University of Hokkaido

1757 Tobetsu, Hokkaido 061-0293, Japan

Phone \& Fax: +81-133-23-1423

E-mail: polan@hoku-iryo-u.ac.jp

\title{
Practice and Knowledge of Health Personnel on Impact of Medical Wastes in Upazilla Health Complexes under Dhaka Division in Bangladesh
}

\begin{abstract}
:
A cross-sectional study was conducted among 42 health personnel and people without a medical background but concerned with the waste management. They were interviewed through pretested semistructured questionnaires at their working places of the upazilla health complexes at Sreepur, Kapasia, Kaligonj, Shivaloya, Saturia, Savar and Dhamrai under Dhaka division of Bangladesh. A total of 6 respondents (2 doctors, 2 nurses and 2 support staff) from each of the upazillas were recruited. Upazilla health complexes were running with average bed occupancy of $\geq 10 /$ day and where $\geq 10$ health personnel were working. The objective of this study was to assess the practice and knowledge on impact of the medical wastes of the health personnel working in the health complexes. The distribution of the respondents by their responses regarding environmental impact of medical wastes were recorded, analyzed and tabulated. Hundred percent $(100.0 \%)$ respondents said about pollution of air, $89.7 \%$ said about pollution of surface water, $69.0 \%$ said about pollution of ground water, $58.6 \%$ said about open dump with infectious agents, soil pollution, $48.3 \%$ said about enhance spread of infectious diseases by rodent, $34.5 \%$ said about litter and leachate, $20.7 \%$ said about production of methane and greenhouse gases and $10.3 \%$ said about raised environmental temperature due to the increase of greenhouse gases. Regarding the knowledge of environmental impact of medical wastes, doctors and nurses were found to be more knowledgeable than the support staff. The difference was found to be statistically significant.
\end{abstract}

Key words: Medical wastes, Environmental impact, Practice and knowledge, Health personnel, Upazilla Health Complex.

\section{Introduction:}

Medical wastes account for a very small fraction of the total wastes generated by human activities. If they are not treated separately, they make the all other wastes a public health hazard. ${ }^{1}$ There is a lack of waste-management system in governmental healthcare facilities in Bangladesh. ${ }^{2}$ The problem of hospital waste disposal and other toxic hazardous wastes is growing rapidly throughout the world as a direct result of increasing anthropogenic activity and population growth. ${ }^{3}$ Hospital wastes or medical wastes, which pose serious threats to environmental health, require specialized treatment and management prior to their final disposal. Disposing them into dustbins, drains, and canals or finally dumping to the outskirts of the health facility pose serious public health hazards. The problem is getting worse with the increasing number of people seeking health care. The present practice of improper handling of generated hospital wastes in health complexes may have been playing a contributing role in spreading out the hepatitis and HIV diseases. The liquid and solid wastes containing hazardous materials are simply dumped into the nearest drain or open space where they are prone to contaminate the ragpickers and can contaminate adjacent environment. 
The chances of infection are become very high to the cleaners; concerned people in the facility and to the general population. ${ }^{1}$ The prevalence of diseases that may be transmitted by hospital wastes are alarming in Bangladesh. There is evidence of hepatitis B infection among 10 percent of children and 30 percent adults. About 5 per cent of the total population in Bangladesh is thought to suffer from chronic hepatitis B infection. Although cases of HIVIAIDS are low in Bangladesh in comparison to neighbouring countries, nevertheless the numbers are rising. ${ }^{4}$ It is noted here that much of the clinical wastes like, syringes, needles, saline drips, discarded foods, gauzes, vials and ampoules are collected by women and children who re-sell these despite of the deadly health risks. It is estimated that hospital wastes account for a very small fraction, notably, only about $1 \%$ of the total solid wastes generated in Bangladesh. In a report from the World Bank $^{5}$, only $10 \%-25 \%$ of the hospital wastes are infectious or hazardous. The amount of such hazardous waste is quite small in figure and until recently this is not handled properly. ${ }^{6}$ Mixing with the domestic solid wastes; the total waste stream becomes potentially hazardous. Upazilla health complexes are unique feature of health care delivery system of Bangladesh health system. These facilities serve as a first referral institution with all available composite services delivered by health system; here a substantial amount of wastes generated every day which can cause serious hindrance to patient care to, people and environment. This study will serve try to unveil possible scenario at such an important strata of the health system and try to find possible way out. Awareness among the health personnel and the personnel associated with healthcare waste management is essential to minimize their risk and also to save the environment and general people from the hazardous medical wastes. Not much research was conducted in Bangladesh to assess the scenario health care waste management and people's understanding about the issue. This study will unveil the level of awareness among the managers of health facility and the health personnel which will help the policy maker to pinpoint and prioritize intervention need in combating the alarming issue. Thus, the objective of this study was to assess practice of method for disposal of medical waste and also the knowledge of health personnel on impact of medical wastes in upazilla health complexes in Bangladesh.

\section{Methodology:}

This study was a cross-sectional study and was conducted at upazilla health complexes situated at Sreepur, Kapasia, Kaligonj, Shivaloya, Saturia, Savar and Dhamrai upazillas under Dhaka division of Bangladesh. The study population was the health personnel working in upazilla health complexes and people without a medical background but concerned with the waste management. The data were collected from March 2009 to July 2009. The study was conducted among health personnel of the above mentioned upazilla health complexes. Health personnel were selected purposively considering feasibility and also convenience of the researchers. Six (6) respondents concerned with waste management (2 doctors, 2 nurses and 2 support staff) from each of the above upazillas were recruited $(n=6 \times 7=42)$. The sampling technique was purposive.

The inclusion criteria of health care facility were:

i. Provides health care that has the potential to generate medical wastes which include labor and operation theatre facility, diagnostic centre deals with invasive blood and other investigation.

ii. Upazilla health complexes with average bed occupancy $\geq 10 /$ day.

iii. Having $\geq 10$ health personnel working.

iv. Willingness of the upazilla health and family planning officer (UHFPO) to participate.

The inclusion criteria of interviewee were:

i. Health personnel working in the facility for more than 2 years.

ii. Nursing staff working in the field for more than 2 years.

iii. Support staff (ward boys /sweepers) working in the field for more than 2 years.

Persons did not consent to participate were excluded from this study.

Data were collected by using semi-structured questionnaire for interview and checklist for facility assessment. In depth interview was conducted by the researchers at the selected health complexes of the recruited health personnel upon their consent and convenience. Pretested semi-structured questionnaire were used for interviewing of health personnel. A checklist prepared based on international best practice and world health organization (WHO) guides line was used to assess the waste management of the health complex. Facility assessment was conducted by the researchers themselves. Collected data with both questionnaire interview and checklist for facility assessments were sorted and coded. Then the data were entered in to the SPSS template. Data analysis was done after necessary screening and cleaning. Level of knowledge was assessed by coding. All the correct answers of the respondents regarding knowledge about medical wastes were marked as 1 and for non response and incorrect answers were marked as 0 (zero). 
Results:

Distribution of the respondents was categorized by the profession the respondents were involved with. Among the respondents, $14(33.3 \%)$ of each were doctors, nurses and ward boys or sweepers (fig.1). In case of the practice of the method of waste disposal, most of the upazillas had been practicing the land-filling for dumping the waste but segregating the different types of wastes, plastic bins and written disposal protocols were not available. Sometimes wastes were disposed into nearby ditches, dustbins and land burial but there were no existence of incinerators. Transportations were not available for carrying the wastes from the hospital (table-1). The distribution of the respondents by their responses regarding environmental impact of medical wastes, among them, $100.0 \%$ said about pollution of air, $89.7 \%$ said about pollution of surface water, $69.0 \%$ said about pollution of ground water, $58.6 \%$ said about open dump with infectious agents, soil pollution, $48.3 \%$ said about enhanced spread of infectious diseases by rodent, $34.5 \%$ said about litter and leachate, $20.7 \%$ said about production of methane and greenhouse gas and $10.3 \%$ said about raised environmental temperature due to increase of the greenhouse gases (table-2). In comparison of the distribution of the knowledge about environmental impact of medical waste, among the respondents, doctors and nurses were found to be more knowledgeable than the support staff. The difference was found to be statistically significant $(p<0.05) \quad($ table-3). Furthermore, the distribution of the level of knowledge about environmental effect of medical wastes, among the respondents, 11.9 $\%$ had excellent knowledge, $7.1 \%$, good knowledge, $14.3 \%$, fair knowledge and $19.0 \%$ had poor knowledge, and $47.6 \%$ were totally ignorant of the said topic (table-4).

\section{Figure 1: Type of personnel interviewed}

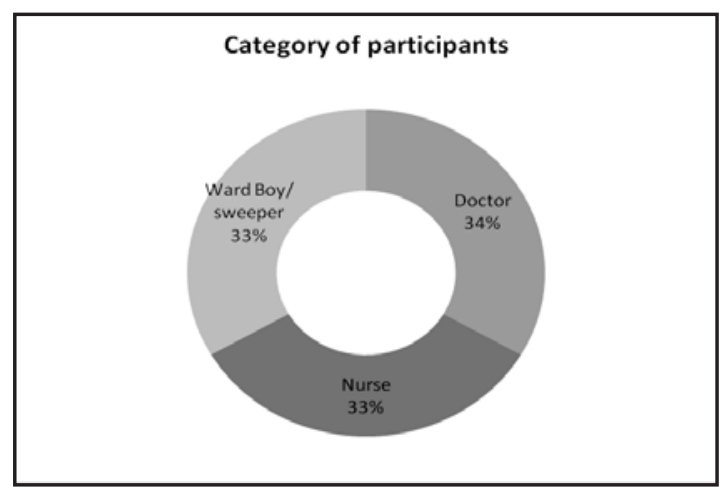

Table-1: Distribution of practice of waste management in different hospitals.

\begin{tabular}{|c|c|c|c|c|c|c|c|}
\hline & Sreepur & Kapasia & Kaligonj & Shivaloya & Saturia & Savar & Dhamrai \\
\hline $\begin{array}{l}\text { Dedicated place of } \\
\text { disposal }\end{array}$ & No & No & No & No & No & No & No \\
\hline $\begin{array}{l}\text { Specific land } \\
\text { (land fill) }\end{array}$ & yes & yes & yes & Yes & yes & yes & No \\
\hline Incinerator & No & No & No & No & No & No & No \\
\hline Dustbin & yes & yes & yes & Yes & yes & yes & yes \\
\hline Storage area (central) & No & No & No & yes & No & No & No \\
\hline $\begin{array}{l}\text { Storage area (section } \\
\text { wise) }\end{array}$ & No & No & No & No & No & No & No \\
\hline Land of burial & yes & yes & yes & yes & yes & yes & yes \\
\hline $\begin{array}{l}\text { Through into } \\
\text { nearby ditch }\end{array}$ & yes & yes & yes & yes & yes & yes & yes \\
\hline Transport through truck & No & No & No & No & No & No & No \\
\hline Having recycle facility & No & No & No & No & No & No & No \\
\hline $\begin{array}{c}\text { Separate pharma waste } \\
\text { disposal }\end{array}$ & No & No & No & No & No & No & No \\
\hline $\begin{array}{l}\text { Segregate of sharp } \\
\text { waste }\end{array}$ & No & No & No & No & No & No & No \\
\hline $\begin{array}{c}\text { Use Long black plastic } \\
\text { bin of DGHS }\end{array}$ & No & No & No & Yes & No & No & No \\
\hline $\begin{array}{c}\text { written waste disposal } \\
\text { protocol }\end{array}$ & No & No & No & No & No & No & No \\
\hline
\end{tabular}

Table-2: Response regarding Environmental impact of medical waste

\begin{tabular}{|l|c|c|}
\hline Response on environmental impact of medical waste & Frequency & Percentage \\
\hline Pollution of air & 29 & $100.0 \%$ \\
\hline Pollution of surface water & 26 & $89.7 \%$ \\
\hline Pollution of ground water & 20 & $69.0 \%$ \\
\hline Open dump with infectious agents, soil pollution & 17 & $58.6 \%$ \\
\hline Enhance spread infectious diseases by rodent & 14 & $48.3 \%$ \\
\hline Litter, leachate & 10 & $34.5 \%$ \\
\hline Production of methane and green house gas & 6 & $20.7 \%$ \\
\hline $\begin{array}{l}\text { Enhanced environmental temperature due to increased green } \\
\text { house gas }\end{array}$ & 3 & $10.3 \%$ \\
\hline
\end{tabular}

Multiple responses

Table-3: Knowledge about environmental effect of medical waste

\begin{tabular}{|l|c|c|c|}
\hline Type of respondents & Correct response & Incorrect response & Total \\
\hline Doctor & $12(85.7 \%)$ & $2(14.3 \%)$ & $14(100.0 \%)$ \\
\hline Nurse & $11(78.6 \%)$ & $3(21.4 \%)$ & $14(100.0 \%)$ \\
\hline Ward boy / sweeper & $6(42.9 \%)$ & $8(57.1 \%)$ & $14(100.0 \%)$ \\
\hline
\end{tabular}

Chi-Square $=6.91 \mathrm{df}=2 \mathrm{P}=.032$

Table-4: Level of Knowledge about Environmental effect of medical waste

\begin{tabular}{|l|c|c|}
\hline Level of Knowledge & Frequency & Percentage \\
\hline Excellent & 5 & 11.9 \\
\hline Good & 3 & 7.1 \\
\hline Fair & 6 & 14.3 \\
\hline Poor & 8 & 19.0 \\
\hline No Knowledge & 20 & 47.6 \\
\hline Total & 42 & 100.0 \\
\hline
\end{tabular}




\section{Discussion:}

The prevalence of diseases that may be transmitted by hospital wastes is alarming in Bangladesh. There is evidence of hepatitis B infection among $10 \%$ of children and $30 \%$ of adults. About $5 \%$ of the total population in Bangladesh is thought to suffer from chronic hepatitis B infection. Although cases of HIVIAIDS are low in Bangladesh in comparison to neighbouring countries, nevertheless the numbers are rising.7 According to current investigation, among the 7 upazillas, all but one had dedicated place of waste disposal, or specific space for landfill or incinerator at the facility, and only one health complex had dedicated central storage site. None of the upazillas had recycle facility for medical wastes or separate pharmacologic waste disposal system. Only one upazilla was found to use black-bin supplied by the director general of health services (DGHS) of Bangladesh government and none had a written protocol for waste management. The amount of waste produced by the upazilla health complexes varies from $15.5 \mathrm{~kg} /$ day to around $30 \mathrm{~kg} /$ day. Considering the production of such wastes as inhabitable for ultimate betterment of people, the action should be aimed to minimization of impact on individual and environment.

Although treatment and disposal of health-care wastes aim at reducing risks, indirect health risks may occur through the release of toxic pollutants into the environment through treatment or disposal. Land filling can potentially result in contamination of drinking water. Occupational risks may be associated with the operation of certain disposal facilities. Inadequate incineration or incineration of materials unsuitable for incineration can result in the release of pollutants into the air. The incineration of materials containing chlorine can generate dioxins and furans3, which are classified as possible human carcinogens and have been associated with a range of adverse effects. Incineration of heavy metals or materials with high metal contents (in particular lead, mercury and cadmium) can lead to the spread of heavy metals in the environment. Dioxins, furans and metals are persistent and accumulate in the environment. Materials containing chlorine or metal should therefore not be incinerated. Only modern incinerators are able to work at $800-1000^{\circ} \mathrm{C}$, with special emission-cleaning equipment, can ensure that no dioxins and furans (or only insignificant amounts) are produced. Smaller devices built with local materials and capable of operating at these high temperatures are currently being field-tested and implemented in a number of countries. At present, there are practically no environment-friendly, lowcost options for safe disposal of infectious wastes. Incineration of wastes has been widely practised, but alternatives are becoming available, such as autoclaving, chemical treatment and microwaving, and may be preferable under certain circumstances. Land-filling may also be a viable solution for parts of the waste stream if practised safely. However, action is necessary to prevent the important disease burden currently created by these wastes. The distribution of the respondents by their responses regarding environmental impact of medical wastes, $100.0 \%$ said about pollution of air, $89.7 \%$, pollution of surface water, $69.0 \%$, pollution of ground water, $58.6 \%$, open dump with infectious agents and soil pollution, $48.3 \%$, enhanced spread of infectious diseases by rodent, $34.5 \%$, litter and leachate, $20.7 \%$, production of methane and greenhouse gases and $10.3 \%$ said about raised environmental temperature due to the increase of greenhouse gases (table-4).

Lack of manpower and also the lack of awareness among the managers regarding hospital waste and its potential have been identified by the respondents in the study as a huge factor for the hindrance in the sector.

In this study, it was evaluated that knowledge about environmental impact of medical wastes. Among the respondents, doctors and nurses were found to be more knowledgeable than the support staff. The difference was found to be statistically significant.

Incorrect disposal of health-care wastes creates other health risks. The unsafe disposal of health-care wastes such as, contaminated syringes and needles pose serious public health risks. Contaminated needles and syringes represent a particular threat as the failure to dispose of them safely may lead to dangerous recycling and repackaging which lead to unsafe reuse. Contaminated injection equipment may be scavenged from waste areas and dumpsites and either are reused or sold to be used again. WHO estimated that, in 2000 , contaminated injections with contaminated syringes caused 21 million hepatitis B virus (HBV) infections (32\% of all new infections), 2 million hepatitis $C$ virus (HCV) infections (40\% of all new infections) and at least 260,000 HIV infections (5\% of all new infections). 8 In 2002, the results of a WHO assessment conducted in 22 developing countries showed that the proportion of health-care facilities that do not use proper waste disposal methods ranges from $18 \%$ to $64 \%$. Medical wastes from health facilities pose huge threats to people, health personnel and environment as well. Unlike the ordinary household wastes, medical wastes are highly infectious and hazardous.

\section{Conclusions:}

As the awareness regrading different types of hospital wastes among health personnel and managers were low, initiatives should be made to raise their knowledge and awareness regarding the issue. Most health complexes are at lack of established waste disposal system, such system should be installed at all Health complexes for proper disposal of waste generated in the facility.

\section{References:}

1. Survey report on hospital waste management in Dhaka city, WSP and PRISM Bangladesh, May 2005.

2. Hassan MM, Ahmed SA, Rahman KA. et al. Pattern of medical waste management: existing scenario in Dhaka City, Bangladesh. BMC Public Health 2008; 8:36.

3. Akter N, Hussain Z, Trankler J, et al. Hospital waste management and its probable health effect: a lesson learned from Bangladesh. Indian J of Environ Health 2002; 44(2):124-37

4. Ahmed A. Hospital waste management: problems and strategic solutions. Dhaka: Independent University, Bangladesh (IUB). 2000.

5. Li CS, Jenq FT. Physical and chemical composition of hospital waste. Infection Control Hosp Epidemiol 1993; 14:145-50.

6. Medical waste disposal, dangerous indifferences. The Bangladesh Observer 2000; Feb 25.

7. Waste concern, presentation on clinical waste management, workshop on effective options for biomedical waste management, August 31, 2003, Dhaka, Bangladesh.

8. Health care-waste management; http://www.who.int/ mediacentre/factsheets/fs281/en/index.html 